\title{
Ecological characteristics contribute to sponge distribution and tool use in bottlenose dolphins Tursiops sp.
}

\author{
Julian A. Tyne ${ }^{1, *}$, Neil R. Loneragan ${ }^{1}$, Anna M. Kopps ${ }^{2,3}$, Simon J. Allen ${ }^{1}$, \\ Michael Krützen ${ }^{1,2,3}$, Lars Bejder ${ }^{1}$
}

\begin{abstract}
${ }^{1}$ Murdoch University Cetacean Research Unit, Centre for Fish, Fisheries and Aquatic Ecosystem Research, School of Biological Sciences and Biotechnology, Murdoch University, South Street, Murdoch, Western Australia 6150, Australia

${ }^{2}$ Evolution \& Ecology Research Centre, School of Biological, Earth and Environmental Sciences, University of New South Wales, Sydney, New South Wales 2052, Australia

${ }^{3}$ Evolutionary Genetics Groups, Anthropological Institute and Museum, University of Zurich, Winterthurerstr. 190, 8057 Zurich, Switzerland
\end{abstract}

\begin{abstract}
In Shark Bay, Western Australia, bottlenose dolphins Tursiops sp. carry conical sponges Echinodictyum mesenterinum on their rostra in the only documented cetacean foraging behaviour using a tool ('sponging'). In this study, we examined the influence of various ecological factors on live sponge distribution and the occurrence of sponging in parts of the western gulf of Shark Bay. We assessed sponge distribution and seagrass cover along 12 transects of approximately $11 \mathrm{~km}$ length, by recording sponges and seagrass in a total of 1380 quadrats $(1 \times 1 \mathrm{~m})$, of which 56 quadrats contained conical sponges. The occurrence of sponging dolphins ('spongers') was documented along 10 of these 12 transects. The distribution of conical sponges was negatively correlated with the distribution of seagrass: no conical sponges were observed in water depths of $<10 \mathrm{~m}$ and no seagrasses were found at depths of $>12 \mathrm{~m}$. A digital elevation model, created from the sample depth data, identified channels in the region. Binary logistic and Poisson loglinear generalised linear models showed that water depth and bathymetric features including channel, substrate and slope were significant in predicting the occurrence and the mean number of conical sponges, as well as that of seagrass. Conical sponge distribution was positively correlated with the distribution of sponging, indicating that ecological factors influence where sponging occurs. The greater number of spongers found in this region may be explained by the larger area of habitat suitable for conical sponges in the western than the eastern gulf of Shark Bay.
\end{abstract}

KEY WORDS: Dolphin behaviour - Social transmission - Digital elevation model · Bathymetry · Shark Bay · Western Australia

Resale or republication not permitted without written consent of the publisher

\section{INTRODUCTION}

The influence of ecological factors on variation in foraging specialisations in marine mammals is still poorly understood. The existence of different foraging specialisations within marine mammal populations has been linked to foraging traditions based on social learning, e.g. bottlenose dolphins Tursiops sp. (Mann \& Sargeant 2003) and sea otters Enhydra lutris (Estes et al. 2003). Yet, the extent to which some of these patterns can be explained by environmental heterogeneity, social transmission, or a combination of both, is one of the key aspects in determining the true extent of social transmission of behaviours in 
marine mammals (Krützen et al. 2005, Sargeant et al. 2007). Unfortunately, disentangling the ecological and behavioural components leading to such patterns is difficult when a particular behaviour cannot be linked directly to a causal ecological factor. Such links however, could be drawn where the foraging behaviour under investigation involves tool use, as the availability of tools should be highly correlated with the occurrence of the behaviour involving the tools.

Tool use, although rare in the animal kingdom, occurs in a wide range of taxa, including insects, fish, birds and mammals (St Amant \& Horton 2008). While in some taxa the ontogeny of tool use appears to be triggered through inherent characteristics (e.g. birds; Kenward et al. 2005), social learning has been invoked in many others (e.g. chimpanzees; Nishida 1973) and is thought to be indicative of advanced cognitive abilities (Rendell \& Whitehead 2001). Invoking social learning as the sole explanation for variation in foraging behaviour within and between animal populations has been carried out by discounting ecological and genetic factors (e.g. McGrew et al. 1997, Whiten et al. 1999, Laland \& Hoppitt 2003, Van Schaik et al. 2003). However, the variation in some foraging behaviours has been found to be at least partly predicted by ecological factors, such as prey behaviour and characteristics, such as variation in ant-dipping behaviour in chimpanzees, which is partly explained by the aggressiveness of the ants (Humle \& Matsuzawa 2002). Thus, a quantitative approach attempting to correlate ecological factors with the occurrence of a behaviour is an important component of enhancing our understanding of how environment shapes behavioural heterogeneity in marine mammal populations. For instance, environmental factors, such as a predictable tidally influenced island wake, have been linked with foraging tactics in wild cetacean populations, such as fin whales Balaenoptera physalus and minke whales $B$. acutorostrata (Johnston et al. 2005), as well as bottlenose dolphins Tursiops truncatus (Hastie et al. 2004).

A long-term study of bottlenose dolphins Tursiops sp. in the eastern gulf of Shark Bay, Western Australia, revealed a diverse array of foraging tactics within this population (Mann \& Sargeant 2003). One of these tactics involved the use of sponges as foraging tools. Dolphins carry conical sponges Echinodictyum mesenterinum on their rostra, a behaviour termed 'sponging' (Smolker et al. 1997). Sponges are thought to serve as a protective tool while the dolphins are foraging for prey in the substratum (Smolker et al. 1997). Several studies have shown that sponging is a foraging tactic exhibited by a minority of individuals within the population (e.g. Mann \& Sargeant 2003), presumably to target prey without swim bladders (Patterson \& Mann 2011). Comparing fatty acid signatures, a long-term indicator of assimilated diet in animals (Iverson et al. 2004), from sponging dolphins (hereafter 'spongers') and non-spongers suggested that sponging enables dolphins to obtain prey that might otherwise not be accessible to them (Kreicker 2010. This further corroborates the notion that sponging is related to foraging and, indeed, might allow differential niche exploitation by dolphins with different foraging tactics (Kreicker 2010).

Sponging by bottlenose dolphins in eastern Shark Bay provided the first evidence of a material culture in cetaceans, with vertical knowledge transfer from mother to offspring (Krützen et al. 2005), a pattern also found in the western gulf of Shark Bay (Ackermann 2008). However, those studies focussed on the potential cultural transmission of sponging behaviour and did not investigate any ecological factors which might affect it. In a different study, Sargeant et al. (2007) found a correlation between sponging behaviour and sponge occurrence in the eastern gulf, emphasising the potential influence of ecological variables on the occurrence of tool-use by bottlenose dolphins. The distribution and morphology of sponges are influenced by a variety of factors such as water flow and depth (Bell \& Barnes 2001), slope gradient (Bell \& Barnes 2000a,b), substratum type and rates of sedimentation (Bell \& Barnes 2000c, Fromont et al. 2006). Factors influencing the distribution of sponges may well affect the distribution of spongers in Shark Bay (Sargeant et al. 2007).

In this study we investigated the relationship between ecological variables that influence sponge distribution and the distribution of spongers and nonspongers in the western gulf of Shark Bay. Our approach expands on that taken by Sargeant et al. (2007) and applies it to a new study site. We used information on habitat depths from $\sim 1400$ quadrats to create a digital elevation model (DEM). This detailed depth data allowed us to identify channel areas and aspects of bathymetry, such as depth and slope of the bottom, which provide an indication of water flow. In particular, we investigated whether the distribution of conical sponges in the western gulf of Shark Bay is affected by physical characteristics of the environment, such as depth, the presence and slope of channels (to infer water flow) and the characteristics of the benthic substratum and habitats. We also examined patterns of conical sponge distribution to determine whether 
they explain some of the variation in the distribution of sponging behaviour in bottlenose dolphins.

\section{MATERIALS AND METHODS}

\section{Study site}

Shark Bay, situated approximately $850 \mathrm{~km}$ north of Perth on the west coast of Australia, is a semienclosed bay (Fig. 1). This system comprises 2 large shallow embayments (the eastern and western gulfs), divided by the Peron Peninsula, as well as numerous islands, and a coastline stretching over $1500 \mathrm{~km}$. The Shark Bay marine environment is relatively shallow throughout and consists of shallow sand flats, embayment plains, and deeper channels (Nahas et al. 2003). Twelve species of seagrass are found in Shark Bay, forming extensive seagrass meadows in the shallower waters, dominated (up to $85 \%$ cover) by one species, Amphibolus antarctica (Walker et al. 1988).

\section{Data collection}

Benthic sampling

A rapid, non-destructive and cost-effective remote video and data management system was developed to record data on benthic habitats in Shark Bay (Tyne et al. 2010). From 21 April to 25 May 2008 we navigated 12 predetermined $11 \mathrm{~km}$ long transects (T1 to T12; Fig. 1) across depth contours in the Denham Channel/Freycinet Reach, using a $5.5 \mathrm{~m}$ boat with a $100 \mathrm{hp}$ outboard. North-south columns of 5 sample points, each $150 \mathrm{~m}$ apart, were selected every $500 \mathrm{~m}$ along these transects, consisting of 23 sampled locations and 115 sample points per transect (Fig. 1). Sampling was undertaken when sea conditions were favourable, i.e. at Beaufort Sea State of 3 or less.

At each sample position, the camera and $1 \mathrm{~m}^{2}$ frame quadrat were lowered to the seabed and a short video of the substrate was captured on the connected laptop (Tyne et al. 2010). Date, time, depth,

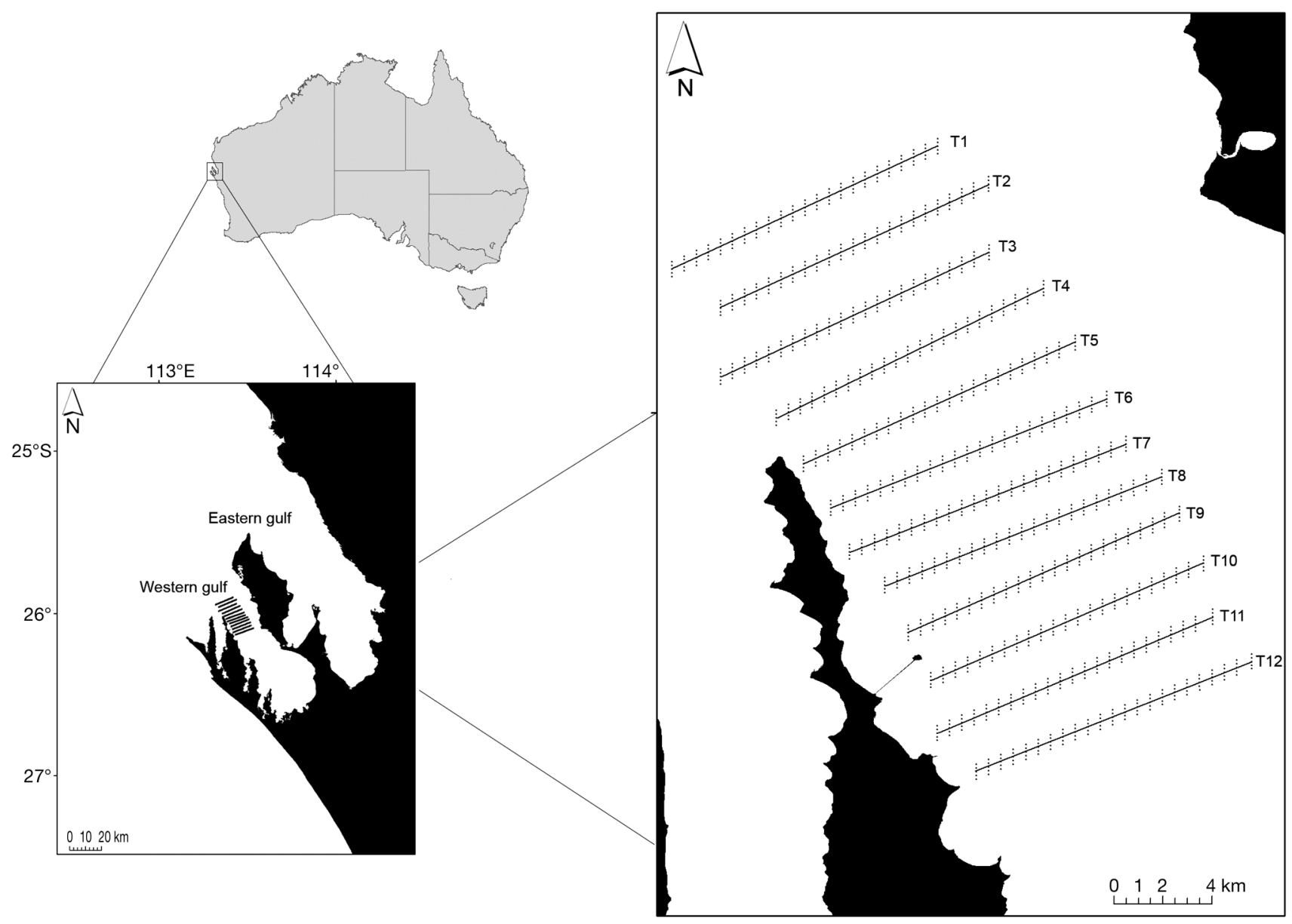

Fig. 1. Transect lines with sample points (115 per transect) where benthic habitats were sampled using a video system to determine the distribution of conical sponges Echinodictyum mesenterinum in the western gulf of Shark Bay, Western Australia 
temperature, and latitude and longitude were recorded. At the end of each sampling day, a data management system was used to analyse the videos (Tyne et al. 2010). The following data were recorded from each video capture of a quadrat: presence/absence of conical sponges, number of conical sponges, presence/absence of seagrass, percentage cover of seagrass and type of substratum. The substratum was categorised qualitatively from each video into one of 3 broad categories: hard, coarse grain or sand.

\section{Dolphin surveys}

Boat based photographic identification and behavioural surveys on dolphin groups (Mann 1999) were conducted in each austral winter between 2007 and 2009. Dolphin groups were surveyed along 10 transects (T3 to T12) over the 3 winters. In 2007 and 2008, each transect was conducted 5 times during the season, while in 2009, a total of 10 runs were completed on each transect due to a longer field season. Dolphins were approached when observed within $300 \mathrm{~m}$ of the transect. During the first $5 \mathrm{~min}$ of an encounter, the predominant dolphin group behaviour (i.e. the activity state of $\geq 50 \%$ of the group members) was categorised into 5 mutually exclusive categories (forage, rest, socialise, travel, or unknown), together with information on whether or not dolphin(s) were wearing a sponge. We also recorded the GPS location of the encounter and water depth. In addition, dolphins in the group were photographed for later identification. When all the dolphins were photographed, and the encounter complete, the transect survey was continued. Dolphins were assumed to be foraging if they were observed performing steep tail out dives or peduncle dives in deep water that last for 1 to $2 \mathrm{~min}$, and if they were also observed wearing a conical sponge during this behavioural state at least once during the 3 field seasons, they were categorised as spongers. This differs slightly from the classification of spongers in the eastern gulf by Mann et al. (2008), who classified individuals as spongers based on $>1$ observation of an individual with a sponge.

\section{Data analysis}

A DEM was interpolated from the depth recordings for each benthic survey sample point to produce an interpretation of the bathymetry of the study site using the IDRISI GIS software. The depth recordings were adjusted for tide height. Channels were classi- fied as areas of the study site where the water depth was $\geq 10 \mathrm{~m}$ and the proportion of these deeper waters was calculated from the DEM for the study site. Because we did not have in situ current measurements, we inferred water flow from the slope of each channel. For example, a fixed volume of water passing through a channel consisting of a steep slope and a narrow width would imply a greater water flow velocity than that of a channel consisting of a more gradual slope and a greater width. The average slope for the eastern and western sides of each sample point were determined by calculating 2 coordinates, 200 and 400 m east and west from each sample point. Using the observed depth at the sample point ( $\left.D_{\text {point }}\right)$ and the modelled depths from the DEM at the 2 calculated coordinates, $200 \mathrm{~m}\left(\mathrm{D}_{200 \mathrm{~m}}\right)$ and $400 \mathrm{~m}\left(\mathrm{D}_{400 \mathrm{~m}}\right)$, the difference in depths at the 200 and $400 \mathrm{~m}$ coordinates to that of the sample point was determined, $\mathrm{S}_{200 \mathrm{~m}}=\mathrm{D}_{\text {point }}-\mathrm{D}_{200 \mathrm{~m}}$ and $\mathrm{S}_{400 \mathrm{~m}}=\mathrm{D}_{\text {point }}-\mathrm{D}_{400 \mathrm{~m}}$. The average slope to the eastern and western $400 \mathrm{~m}$ point was calculated $\left(=\left[\mathrm{S}_{400 \mathrm{~m}}-\mathrm{S}_{200 \mathrm{~m}}\right] / 2\right)$, where $\mathrm{S}_{400 \mathrm{~m}}=$ slope to $400 \mathrm{~m}$ from the sample point and $\mathrm{S}_{200 \mathrm{~m}}=$ slope to $200 \mathrm{~m}$ from the sample point.

The spatial distributions of sponges and seagrass were examined using IDRISI 15.01 Andes Edition GIS software (linked to the data management system) with the appropriate Seafarer nautical chart (AUS749). Point vector files indicating the presence/absence and number of conical sponges, as well as the presence/ absence and percentage cover of seagrass were created for each sampling point to produce spatial distribution maps for sponges and seagrass.

\section{Statistical analyses}

Statistical analyses were undertaken using R 2.10.1 (R Development Core Team 2010) and SPSS v16.0.2. Data were accessed directly from the data management system ODBC (Open Database Connectivity) and summary tables and charts were produced. Binary logistic and Poisson log-linear generalised linear models (GLMs) were developed to investigate whether the presence/absence and counts of conical sponges, as well as the presence/absence and percentage cover of seagrass, were significantly related to the presence and position of channels, slope of the bottom, substrate, and water depth.

The relationship between presence and absence of conical sponges or seagrass with the predictor variables was explored using a binary logistic GLM with a link function. The relationship between the number 
of conical sponges or percentage seagrass cover and the predictor variables was explored using a log-linear Poisson GLM with a log-link function, where $\log (\mu)$ is the $\log$ of the mean of the dependent variable. Models with only 1 predictor were created at first. The models with significant predictors were then combined to create multiple predictor models. Akaike's information criterion (AIC) (Akaike 1974), which selects the most parsimonious model that best fit the data by taking into account the variation explained and the number of terms in the model, was used to select the best model. The lower the AIC value, the better the model (Burnham \& Anderson 2002).

The locations of spongers recorded from the 2007 to 2009 surveys were overlaid on the DEM and chart of the study area, indicating which of the 5 channels the dolphins were using (North West, North East, Central, South West and South East; see Fig. 2). All surveys with a sighting of at least 1 sponger were used in the analyses of dolphin distribution and environmental variables. No re-sightings, defined as an encounter of a group with the same composition of a group in an earlier survey on the same day, were included in analyses. A binary logistic

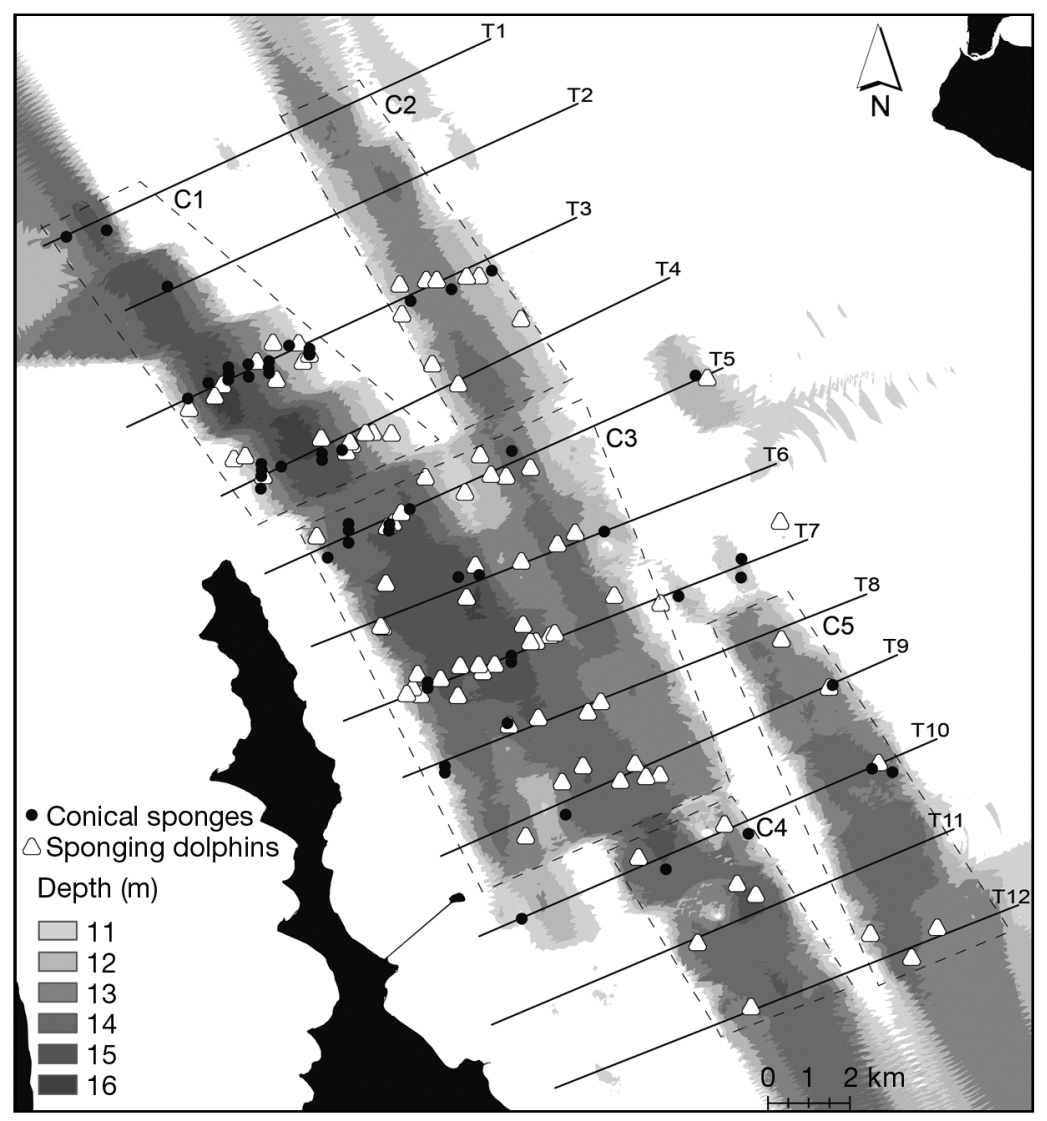

Fig. 2. Spatial distribution of conical sponges Echinodictyum mesenterinum $(\bullet)$ along 12 transects and the spatial distribution of spongers $(\Delta)$ along 10 transects in the western gulf of Shark Bay, Western Australia. Dashed boxes show the extent of the 5 main channels (water depth $\geq 10 \mathrm{~m}$ ) identified from the digital elevation model (C1: North West channel; C2: North East channel; C3: Central channel, C4: South West channel ${ }_{i}$ C5: South East channel)

GLM was developed to test whether water depth and channel were significant in predicting the probability of the occurrence of spongers.

\section{RESULTS}

\section{Bathymetry, sponges and seagrass}

A total of 1380 videos were recorded over an area spanning approximately $248 \mathrm{~km}^{2}$. The DEM of the study area revealed 5 deep channels ( $\geq 10 \mathrm{~m}$ in depth) in the western gulf study area (Fig. 2). The North West channel (C1) had the deepest mean depth $(13.2 \mathrm{~m})$ and the largest number of quadrats with conical sponges (24); while the North East channel (C2) had the shallowest mean depth $(11.8 \mathrm{~m})$ and a low number of quadrats with conical sponges (3) (Fig. 2). The Central channel (C3) was the widest and covered the largest area. Depths of between 15 and
$16 \mathrm{~m}$ were found predominantly in the western areas of the study site from T1 to T6; although T10, T11 and T12 also had small areas where the water depth reached $15 \mathrm{~m}$ (Fig. 2).

Conical sponges were found in $56(4 \%)$ of the 1380 samples. The percentage of quadrats containing conical sponges ranged from $0 \%$ (T11 and T12) to $14 \%$ (T3) and the mean number of conical sponges per quadrat ranged from 0 (T11 and T12) to 0.20 (T3).

The mean depth for the presence of conical sponges was $13.5 \mathrm{~m}$ (range 10.1 to $15.7 \mathrm{~m}$ ). In contrast to conical sponges, seagrass was found only in depths $\leq 11.8 \mathrm{~m}$. The mean depth of quadrats containing seagrass was $7.5 \mathrm{~m}$ and the main species was Amphibolus antarctica.

The probability of the occurrence of conical sponges in a quadrat in relationship to depth was estimated to be 0 until a depth of ca. $6 \mathrm{~m}$, increasing slowly to 0.1 at ca. $14 \mathrm{~m}$ before reaching a maximum of 0.18 at $16 \mathrm{~m}$ 
(Fig. 3A). The predicted probability of seagrass occurrence with depth showed the opposite pattern - the predicted probability of the occurrence of seagrass in a quadrat was 1 until a depth of $6 \mathrm{~m}, 0.8$ at $9 \mathrm{~m}$ and 0 at $12 \mathrm{~m}$ (Fig. 3B). Depth was a significant predictor in the binary logistic GLMs for predicting the occurrence of conical sponges (positive slope), and in predicting the occurrence of seagrass (negative slope) (Table 1). The most parsimonious model for predicting the occurrence of seagrass, as indicated by the lowest AIC

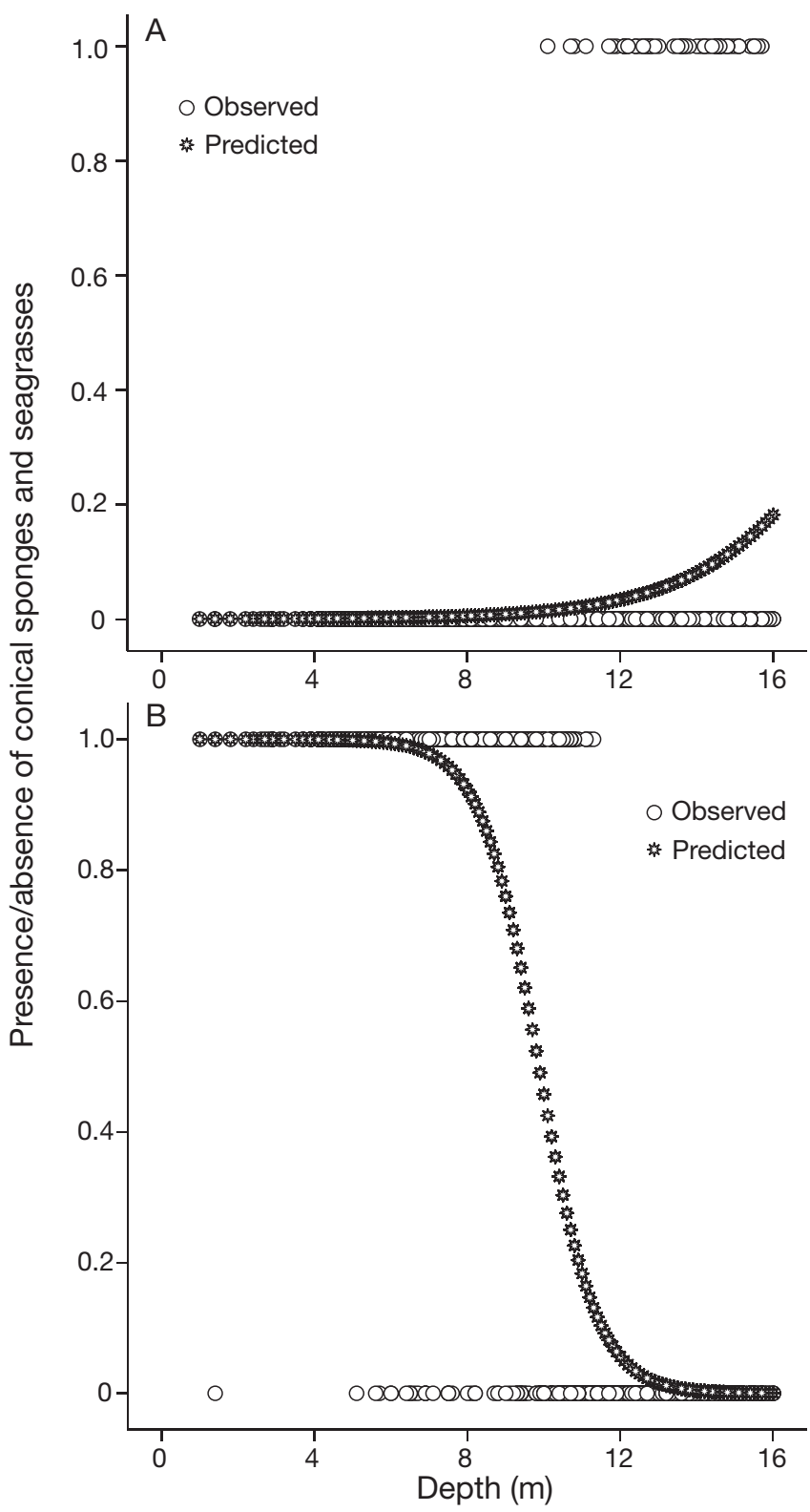

Fig. 3. (A) Conical sponges Echinodictyum mesenterinum and (B) seagrass (primarily Amphibolus antarctica) in relationship to depth. Observed presence/absence (O) and predicted probability of presence (* from a binary logistic generalised linear model
Table 1. Binary logistic generalised linear models showing the relationship between the probabilities of occurrence of conical sponges Echinodictyum mesenterinum, dolphins Tursiops sp. carrying sponges ('spongers') and seagrass (primarily Amphibolus antarctica), with factors Depth, Substrate, Channel and Slope (i.e. eastern slope of channel)

\begin{tabular}{|c|c|c|c|c|}
\hline Model & AIC & df & $\chi^{2}$ & $\mathrm{p}$ \\
\hline \multicolumn{5}{|l|}{ Conical sponges } \\
\hline Depth & 153.43 & 1 & 32.40 & $<0.001$ \\
\hline Substrate, & 72.78 & 2 & 52.40 & $<0.001$ \\
\hline Channel & & 5 & 16.70 & 0.005 \\
\hline \multicolumn{5}{|l|}{ Spongers } \\
\hline Depth & 181.81 & 1 & 49.56 & $<0.001$ \\
\hline Channel $\times$ Depth & 234.55 & 6 & 48.28 & $<0.001$ \\
\hline Channel, & 223.28 & 5 & 14.35 & 0.014 \\
\hline Channel $\times$ Depth & & 6 & 12.30 & 0.050 \\
\hline \multicolumn{5}{|l|}{ Seagrass } \\
\hline Depth & 278.61 & 1 & 302.26 & $<0.001$ \\
\hline Depth, & 551.18 & 1 & 288.37 & $<0.001$ \\
\hline Slope & & 1 & 6.86 & 0.009 \\
\hline Depth, & 510.24 & 1 & 252.10 & $<0.001$ \\
\hline Slope, & & 1 & 26.19 & $<0.001$ \\
\hline Depth $\times$ Slope & & 1 & 30.65 & $<0.001$ \\
\hline
\end{tabular}

value, was the model with depth fitted as the only predictor (Table 1). Depth, substrate and channel were all significant predictors for the occurrence of conical sponges in the binary logistic GLMs, however, the AIC values indicated that the model based on the predictors, substrate and channel, was a better fit to the data (Table 1).

The number of conical sponges increased with increasing depth (Fig. 4). The shape of the curve for the predicted mean number of conical sponges with increasing depth (Fig. 4B) was similar to that of the predicted occurrence of conical sponges (Fig. 3A). In contrast, the predicted mean percentage cover of seagrass decreased with depth; it was approximately $45 \%$ at around $1 \mathrm{~m}$ depth and decreased fairly rapidly to $10 \%$ at about $5 \mathrm{~m}$ depth, before it declined more gradually to about $0.04 \%$ at around $16 \mathrm{~m}$ (Fig. 4D). The model of best fit for predicting the mean number of conical sponges had 3 predictors: substrate, channel and eastern slope (Table 2). The model of best fit to predict the mean percentage cover of seagrass contained depth, channel and 3 interaction terms (Table 2).

\section{Distribution of dolphins in relation to sponge occurrence}

Between 2007 and 2009, 471 dolphin groups were photo-identified whilst on transect (Table 3). 

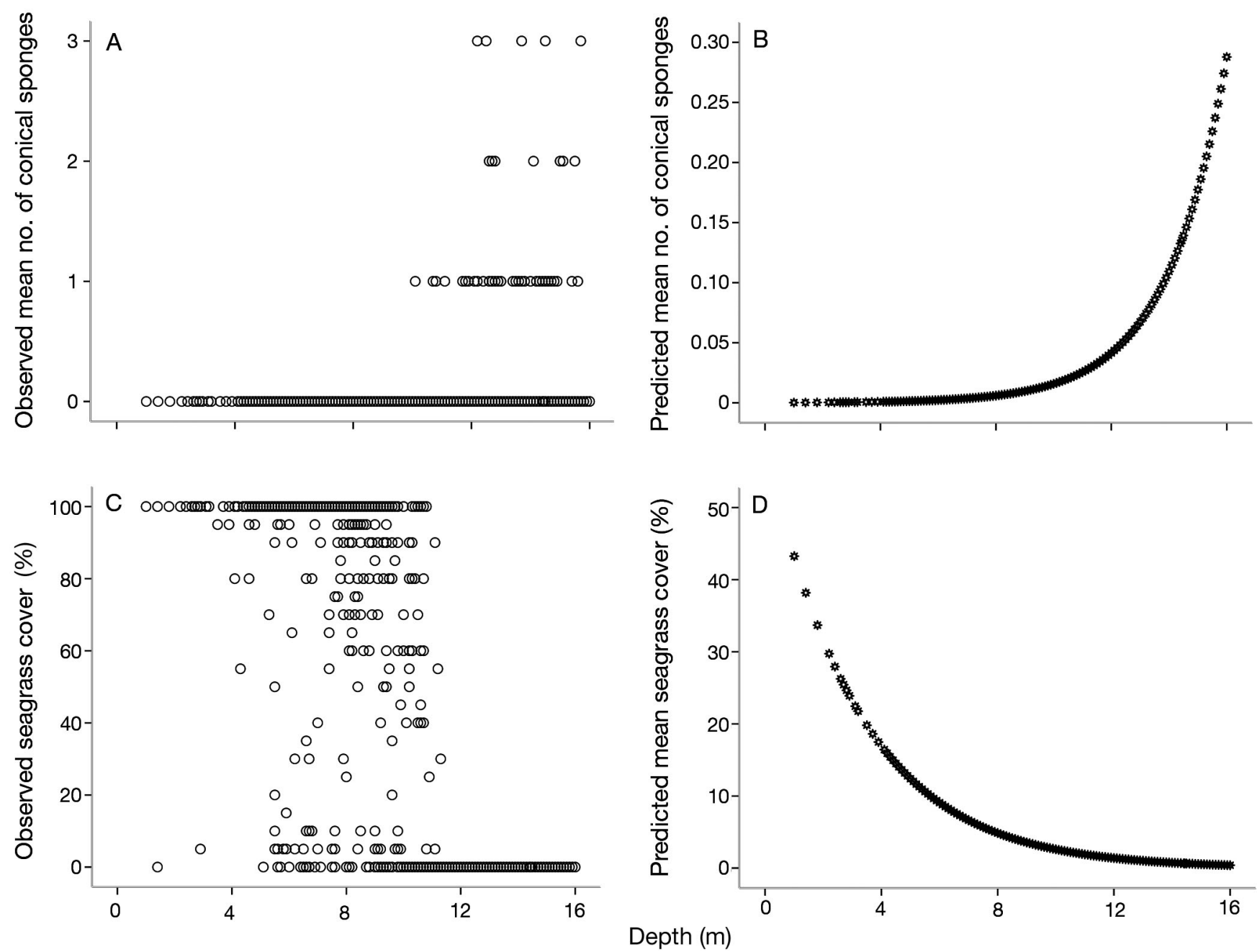

Fig. 4. (A,B) Conical sponges Echinodictyum mesenterinum and (C,D) seagrass (primarily Amphibolus antarctica), in relationship to depth. $(A, C)$ Observed number/cover and $(B, D)$ predicted mean number/cover from a log-linear Poisson generalised linear model

Dolphin groups containing at least 1 sponger were observed on 88 occasions over the 3 seasons; 19 times in 2007, 18 in 2008 and 51 in 2009. A total of 232 individual dolphins were identified while carrying out transect surveys, and 44 of these were observed sponging (Table 3). The predicted probability of occurrence of spongers by depth was 0.01 until a depth of $3.8 \mathrm{~m}$, and then increased slowly to 0.15 at $10 \mathrm{~m}$, reaching its maximum of 0.7 at $\sim 16 \mathrm{~m}$ (Fig. 7). All individual dolphins classified as spongers, including 15 individuals identified while not on transect, were observed predominantly in the deep water channels (>10 m depth), whether or not they were carrying a sponge on their rostra (Table 4).

Conical sponges were only observed in water depths $\geq 10 \mathrm{~m}$ (Figs. $2 \& 6$ ), where 86 out of 88
$(97.7 \%)$ encounters with spongers were recorded. In contrast, only $45 \%$ of all encounters with nonsponging dolphins were recorded in water depths $\geq 10 \mathrm{~m}$, of which $54 \%$ were apparently foraging. The mean water depths of the occurrence of conical sponges and the occurrence of spongers were similar $(\sim 14 \mathrm{~m})$; whereas the mean depth at which non-sponging dolphins were sighted apparently foraging was $9.8 \mathrm{~m}$, about $4 \mathrm{~m}$ shallower than that for spongers (Fig. 8). The depth range of sightings of spongers (9.4 to $16 \mathrm{~m}$ ) was narrower than that for non-sponging dolphins (3.4 to 15.9 m; Fig. 8). About $51 \%$ of our study area in the western gulf was $\geq 10$ in depth compared with only $0.26 \%$ of the study area in the eastern gulf (Sargeant et al. 2007). 
Table 2. Poisson log linear generalised linear models showing the relationship between the probabilities of mean number of conical sponges Echinodictyum mesenterinum and the factors Depth, Substrate, Channel and Slope (i.e. eastern slope of channel) and the percentage coverage of seagrass (primarily Amphibolus antarctica) with relation to Depth. $\mathrm{p}<$ 0.001 for all models

\begin{tabular}{|c|c|c|c|}
\hline Model & AIC & $\mathrm{df}$ & $\chi^{2}$ \\
\hline \multicolumn{4}{|l|}{ Conical sponges } \\
\hline Depth & 543.64 & 1 & 45.70 \\
\hline Substrate, & 396.18 & 2 & 57.36 \\
\hline Channel & & 5 & 28.31 \\
\hline \multicolumn{4}{|l|}{ Seagrass } \\
\hline Depth & 3444.44 & 1 & 1852.82 \\
\hline Depth, & 2960.53 & 1 & 239.41 \\
\hline Channel & & 5 & 319.08 \\
\hline Depth, & 2944.69 & 1 & 163.15 \\
\hline Channel, & & 5 & 328.72 \\
\hline Slope & & 1 & 18.35 \\
\hline Depth, & 2637.53 & 1 & 69.35 \\
\hline Channel, & & 5 & 91.01 \\
\hline Slope, & & 1 & 15.77 \\
\hline Channel $\times$ Depth & & 5 & 95.95 \\
\hline
\end{tabular}

\section{DISCUSSION}

Shark Bay bottlenose dolphins are the only cetaceans known to exhibit tool use to forage (Sargeant et al. 2007). The results from this study suggest that ecological factors, particularly the distribution of conical sponges, have an important influence on the occurrence of sponging in the western gulf of Shark Bay. Conical sponges and spongers were found predominantly in the deeper water channels $(\geq 10 \mathrm{~m}$ in depth). Furthermore, the predicted probability of the occurrence of conical sponges and spongers was correlated with increasing water depth and channel characteristics, such as depth and slope. The type of substratum was also significantly correlated with conical sponges and spongers. The number of spongers recorded during transect and non-transect surveys during this 3 yr study (54) is high compared

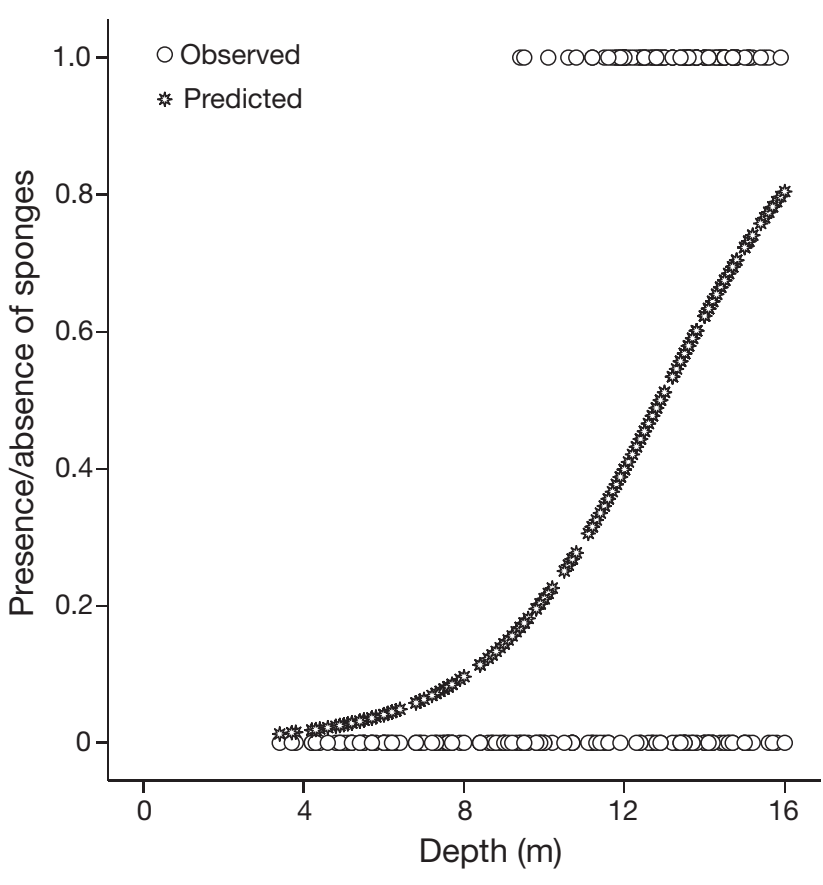

Fig. 5. Tursiops sp. Observed presence/absence (O) and predicted probability of the presence of spongers in relationship to depth from a binary logistic generalised linear model

Table 4. Tursiops sp. Data specific to dolphins observed carrying sponges ('spongers') identified from both transect and non-transect surveys from 2007 to 2009. Channels: depth $\geq 10 \mathrm{~m}$; shallows; depth $<10 \mathrm{~m}$

\begin{tabular}{|lccccc|}
\hline \multirow{2}{*}{ Year } & \multirow{2}{*}{ Ind. } & \multicolumn{4}{c}{ No. of sightings } \\
\cline { 3 - 6 } & & Total & $\begin{array}{c}\text { With } \\
\text { sponges }\end{array}$ & $\begin{array}{c}\text { In } \\
\text { channels }\end{array}$ & In \\
& & & shallows \\
\hline 2007 & 40 & 84 & 54 & 81 & 3 \\
2008 & 39 & 59 & 34 & 55 & 4 \\
2009 & 46 & 135 & 94 & 125 & 10 \\
Total & 54 & 278 & 182 & 261 & 17 \\
\hline
\end{tabular}

with the number (41) observed during 25 yr of field work in the eastern gulf of Shark Bay (Mann et al. 2008).

Table 3. Tursiops sp. Summary of the characteristics of bottlenose dolphin groups observed during transect surveys from 2007 to 2009. Mean \pm SE for each characteristic per transect survey (dolphins were only surveyed on transects T3 to T12) are shown in parentheses

\begin{tabular}{|c|c|c|c|c|c|c|}
\hline \multirow[t]{2}{*}{ Year } & \multirow{2}{*}{$\begin{array}{c}\text { No. of } \\
\text { transect runs }\end{array}$} & \multirow[b]{2}{*}{ Groups observed } & \multicolumn{3}{|c|}{ - Dolphin characteristic (no.) } & \multirow[b]{2}{*}{$\begin{array}{l}\text { Groups with } \\
\text { non-spongers }\end{array}$} \\
\hline & & & Foraging groups & $\begin{array}{l}\text { Non-foraging } \\
\text { groups }\end{array}$ & $\begin{array}{l}\text { Groups with } \\
\text { spongers }\end{array}$ & \\
\hline 2007 & 5 & $124(2.3 \pm 0.15)$ & $68(1.9 \pm 0.15)$ & $56(2.7 \pm 0.16)$ & $19(1.8 \pm 0.18)$ & $46(2.0 \pm 0.15)$ \\
\hline 2008 & 5 & $113(3.0 \pm 0.24)$ & $57(2.1 \pm 0.21)$ & $56(3.8 \pm 0.20)$ & $18(1.6 \pm 0.26)$ & $30(2.4 \pm 0.22)$ \\
\hline 2009 & 10 & $234(2.7 \pm 0.16)$ & $127(1.7 \pm 0.09)$ & $107(4.0 \pm 0.15)$ & $51(1.4 \pm 0.08)$ & $68(1.8 \pm 0.11)$ \\
\hline All years & 20 & $471(2.67 \pm 0.11)$ & $252(1.9 \pm 0.08)$ & $219(3.6 \pm 0.10)$ & $88(1.6 \pm 0.08)$ & $144(2.0 \pm 0.08)$ \\
\hline
\end{tabular}




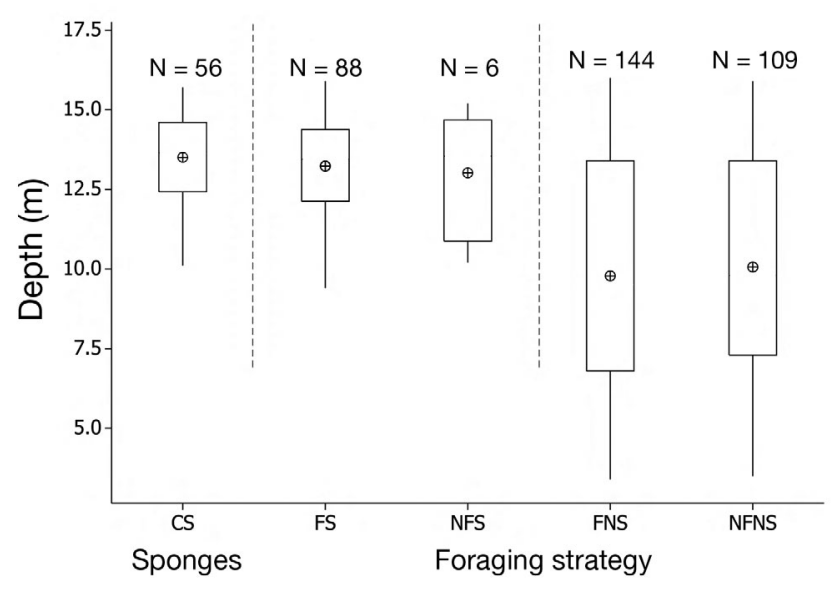

Fig. 6. Mean depth, confidence limits and depth ranges for conical sponges Echinodictyum mesenterinum and 4 different behaviours of dolphins Tursiops sp. along the transect lines. CS: conical sponges; FS: foraging dolphins carrying sponges; NFS: non-foraging dolphins carrying sponges; FNS: foraging non-sponging dolphins; NFNS: non-foraging non-sponging dolphins

Similarly, in the eastern gulf of Shark Bay, sponges and spongers were concentrated primarily in the deeper waters of the channels, and sponge carrying was largely limited to deep waters where sponges were abundant ( $\geq 8 \mathrm{~m}$; Smolker et al. 1997, Sargeant et al. 2007). The channels in the eastern gulf, however, are generally shallower (5 to $6 \mathrm{~cm}$, Nahas et al. 2005) than those in the western gulf (10 to $16 \mathrm{~m}$; Fig. 2). This suggests that water flow, rather than depth alone, predicts sponge distribution and, therefore, the occurrence of sponging behaviour. In general, the distribution and growth of sponges is influenced by factors other than water depth, such as water flow, sedimentation, and type and shape of substrate (Bell \& Barnes 2000a,b, Fromont et al. 2006). Although water flow was not measured in this study, sponge abundance increased in the deeper, narrower channels of the western gulf (i.e. the north western and south eastern regions of the study area; Fig. 2), where water flow may be an important contributing factor to providing suitable habitat for sponges. Increased water flow is also likely to enhance the growth of sponges (Bell \& Barnes 2000c).

We might expect sponging behaviour to be explained by one or more, or a combination of, 3 factors: some genetic predisposition, ecological characteristics, and social learning. Krützen et al. (2005) presented evidence for social learning, rather than genes or ecological characteristics determining sponging in the eastern gulf of Shark Bay. Acker- mann (2008) found a similar pattern in the west. However, neither of these studies examined the significance of environmental factors. In the eastern gulf, Sargeant et al. (2007) found evidence of ecological correlates with sponging behaviour. This study extended the approach of Sargeant et al. (2007), and assessed sponge distribution in the west and the ecological factors that seem to promote sponge presence and abundance. In the western gulf, we found (1) that many sponges occurred in deeper water with steeper eastern slopes, which is an indicator of higher water flow and likely to provide conditions that enhance sponge growth, (2) a large area of suitable habitat for the presence and growth of sponges and (3) the presence of many spongers. Thus, our data suggests that ecological conditions contribute to where sponging occurs in our study area in the western gulf. However, the relative contributions of ecological characteristics vs. social learning to the distribution of sponging behaviour by dolphins is unclear.

In the study area of the western gulf of Shark Bay, a total of 54 individually identified spongers were recorded during 3 field seasons. In contrast, only 41 spongers have been identified over $25 \mathrm{yr}$ of research in the eastern gulf region (Mann et al. 2008). An individual in the eastern gulf, however, was only classified as a sponger if it had been observed carrying a sponge on $>1$ occasion (Mann et al. 2008), compared to only once in this study. The western gulf study area consists of $51 \%$ deep habitat ( $>10 \mathrm{~m}$ in depth), compared with just $0.26 \%$ in the eastern study area (Heithaus \& Dill 2002). Since both gulf study areas are of similar sizes (eastern gulf $=286 \mathrm{~km}^{2}$, western gulf $=248 \mathrm{~km}^{2}$ ), it appears that the western gulf provides a substantially greater area favourable to conical sponges and spongers. This suggests that the greater number of spongers found in the western gulf is further evidence of the contribution of ecological factors to the distribution of sponging behaviour, rather than an artefact of the different definitions of sponger between gulfs.

In addition to the location of channels, depth and the distribution of sponges, prey distribution may have an important influence on the distribution of spongers (Sargeant et al. 2007, Mann et al. 2008, Patterson \& Mann 2011). Spongers were observed where sponges were located, but no conical sponges found. Thus, dolphins may transport conical sponges to areas where they do not grow in order to take advantage of prey in these locations (Patterson \& Mann 2011). Patterson \& Mann (2011) identified potential prey items of spongers in the eastern gulf of Shark Bay. Determining the distribution of these prey items 
in relation to conical sponge distribution could elucidate whether or not spongers transport conical sponges to areas in which they do not grow.

\section{Environment and habitat features}

The bathymetry of the western gulf study site consists of deep, relatively narrow channels in the northwest and southeast of the study area, with the deepest water in the northwest area. These are areas where the current flow is likely to be more favourable to sponges. The highest numbers of conical sponges were found in the north western region of the study site. The abundance of sponges was also reported to increase in the deep channels of the eastern gulf of Shark Bay (Bell \& Barnes 2000b). In the western gulf, the tidal magnitude increases as the gulf narrows (Nahas et al. 2005). Since the western gulf narrows to the south in comparison to the eastern gulf and the channels are deeper, water flow is expected to be faster in some areas in the western than eastern gulf. This provides a greater area of favourable environments for the growth of sponges than that in the eastern gulf, where sponges are restricted to the few channels between sand banks.

Sponges are generally highly competitive in colonising the benthic substratum (Bell \& Barnes 2000c). However, they are often overgrown by organisms such as ascidians, soft corals, and some species of algae (Bell \& Barnes 2000c). No sponges were seen in the quadrats that contained seagrasses from the 1380 video recordings completed during this study. The absence of sponges from the shallower habitats (<10 $\mathrm{m}$ in depth) could be explained by unfavourable ecological conditions for sponge growth (e.g. low water flow due to predominance of seagrasses), unsuitable substratum, and competition for space by seagrasses in these areas.

\section{Conclusions}

This study has demonstrated significant relationships between water depth, the presence of channels that promote water flow and the occurrence of sponging by bottlenose dolphins. The bathymetry of the study area appears to be influential in determining the distribution of sponges in the region. Ecological factors, such as water depth and channel presence, were significant in predicting the presence of conical sponges, which, in turn, was significant in predicting the occurrence of sponging behaviour in the bottlenose dolphin community. The large number of spongers documented in the western gulf study area during only 3 yr may be an indication that the western gulf study area is a more ecologically favourable area for sponging behaviour than the eastern gulf of Shark Bay. Information on substratum type and slope of other deep water areas $(\geq 10 \mathrm{~m})$ in the western gulf was unavailable for this study. Depth, however, was significant in predicting the occurrence of both conical sponges and spongers. Future research efforts in the western gulf of Shark Bay should concentrate on other deep water areas to assess substrate and slope (or indeed direct measures of water flow) and, therefore, suitability of sponge and sponger habitat. Including other areas for comparison might better resolve the relative contributions of the ecological and social factors driving tool use in Shark Bay's bottlenose dolphins.

Acknowledgements. The authors thank Shark Bay Resources and Mitsui for their extensive logistical support in this project and the Useless Loop community for making us feel so at home while conducting field work. The National Geographic Society, Sea World Research and Rescue Foundation, Claraz-Schenkung Switzerland, the A. H. Schultz Foundation Switzerland, Julius-Klaus Foundation Switzerland, University of Zurich and Murdoch University provided financial support. We also thank H. Whitehead for his comments on the manuscript, $\mathrm{H}$. Kobryn for help with the study area maps and M. Pepper for his invaluable assistance in the field. We thank the 3 anonymous reviewers and the editor of MEPS for their time and constructive comments on the manuscript. The study was carried out under permits SF002958, SF007046, SF006160 and SF006608 from the Department of Environment and Conservation. The research was carried out with Murdoch University Animal Ethics Committee approval (NS2240) and ethics approval obtained from the University of New South Wales (99_52 and 08/33B).

\section{LITERATURE CITED}

Ackermann C (2008) Contrasting vertical skill transmission patterns of a tool use behaviour in two groups of wild bottlenose dolphins (Tursiops sp.), as revealed by molecular genetic analysis. Masters thesis, University of Zurich

Akaike H (1974) A new look at the statistical model identification. Automatic Control. IEEE Trans Biomed Eng 19: 716-723

Bell JJ, Barnes DKA (2000a) The distribution and prevalence of sponges in relation to environmental gradients within a temperate sea lough: inclined cliff surfaces. Divers Distrib 6:305-323

Bell JJ, Barnes DKA (2000b) The distribution and prevalence of sponges in relation to environmental gradients within a temperate sea lough: vertical cliff surfaces. Divers Distrib 6:283-303

Bell JJ, Barnes DKA (2000c) A sponge diversity centre within a marine 'island'. Hydrobiologia 440:55-64 
Bell JJ, Barnes DKA (2001) Sponge morphological diversity: a qualitative predictor of species diversity? Aquat Conserv 11:109-121

Burnham KP, Anderson DR (2002) Model selection and mutimodel inference: a practical information-theoretic approach. Springer Science + Business Media, New York, NY

- Estes JA, Riedman ML, Staedler MM, Tinker MT, Lyon BE (2003) Individual variation in prey selection by sea otters: patterns, causes and implications. J Anim Ecol 72: 144-155

Fromont J, Vanderklift MA, Kendrick GA (2006) Marine sponges of the Dampier Archipelago, Western Australia: patterns of species distributions, abundance and diversity. Biodivers Conserv 15:3731-3750

Hastie GD, Wilson B, Wilson LJ, Parsons KM, Thompson PM (2004) Functional mechanisms underlying cetacean distribution patterns: hotspots for bottlenose dolphins are linked to foraging. Mar Biol 144:397-403

> Heithaus MR, Dill LM (2002) Food availability and tiger shark predation risk influence bottlenose dolphin habitat use. Ecology 83:480-491

- Humle T, Matsuzawa T (2002) Ant-dipping among the chimpanzees of Bossou, Guinea, and some comparisons with other sites. Am J Primatol 58:133-148

Iverson SJ, Field C, Don Bowen W, Balanchard W (2004) Quantitative fatty acid signature analysis: a new method of estimating predator diet. Ecol Monogr 74:211-235

Johnston DW, Thorne LH, Read AJ (2005) Fin whales Balaenoptera physalus and minke whales Balaenoptera acutorostrata exploit a tidally driven island wake ecosystem in the Bay of Fundy. Mar Ecol Prog Ser 305: 287-295

Kenward B, Weir AAS, Rutz C, Kacelnik A (2005) Tool manufacture by naive juvenile crows. Nature 433:121

Kreicker S (2010) Culturally transmitted tool use in bottlenose dolphins (Tursiops sp.) - utilization of an unexploited niche? Masters thesis, University of Zurich

Krützen M, Mann J, Heithaus MR, Connor RC, Bejder L, Sherwin WB (2005) Cultural transmission of tool use in bottlenose dolphins. Proc Natl Acad Sci USA 102: 8939-8943

Laland KN, Hoppitt W (2003) Do animals have culture? Evol Anthropol 12:150-159

Mann J (1999) Behavioral sampling methods for cetaceans: a review and critique. Mar Mamm Sci 15:102-122

Mann J, Sargeant B (2003) Like mother, like calf: the ontogeny of foraging traditions in wild Indian ocean bottlenose dolphins (Tursiops sp.). In: Fragaszy D, Perry

Editorial responsibility: Steve Dawson, Dunedin, New Zealand
S (eds) The biology of traditions. Cambridge University Press, Cambridge, p 236-266

Mann J, Sargeant BL, Watson-Capps JJ, Gibson QA, Heithaus MR, Connor RC, Patterson E (2008) Why do dolphins carry sponges? PLoS ONE 3:e3868

McGrew WC, Ham RM, White LJT, Tutin CEG, Fernandez M (1997) Why don't chimpanzees in Gabon crack nuts? Int J Primatol 18:353-374

Nahas EL, Jackson G, Pattiaratchi CB, Ivey GN (2003) Hydrodynamic modelling of snapper Pagrus auratus egg and larval dispersal in Shark Bay, Western Australia: reproductive isolation at a fine spatial scale. Mar Ecol Prog Ser 265:213-226

Nahas EL, Pattiaratchi CB, Ivey GN (2005) Processes controlling the position of frontal systems in Shark Bay, Western Australia. Estuar Coast Shelf Sci 65:463-474

$>$ Nishida T (1973) The ant-gathering behaviour by the use of tools among wild chimpanzees of the Mahali Mountains. J Hum Evol 2:357-370

Patterson EM, Mann J (2011) The ecological conditions that favor tool use and innovation in wild bottlenose dolphins (Tursiops sp.). PLoS ONE 6:e22243

R Development Core Team (2009) R: A language and environment for statistical computing. R Foundation for Statistical Computing, Vienna

Rendell L, Whitehead H (2001) Culture in whales and dolphins. Behav Brain Sci 24:309-324

> Sargeant BL, Wirsing AJ, Heithaus MR, Mann J (2007) Can environmental heterogeneity explain individual foraging variation in wild bottlenose dolphins (Tursiops sp.)? Behav Ecol Sociobiol 61:679-688

> Smolker RS, Richards A, Connor R, Mann J, Berggren P (1997) Sponge carrying by dolphins (Delphinidae, Tursiops sp.): a foraging specialization involving tool use? Ethology 103:454-465

St Amant R, Horton TE (2008) Revisiting the definition of animal tool use. Anim Behav 75:1199-1208

> Tyne JA, Loneragan NR, Krützen M, Allen SJ, Bejder L (2010) An intergrated data management system and video system for sampling aquatic benthos. Mar Freshw Res 61:1023-1028

- Van Schaik CP, Ancrenaz M, Borgen G, Galdikas B and others (2003) Orangutan cultures and the evolution of material culture. Science 299:102-105

> Walker DI, Kendrick GA, McComb AJ (1988) The distribution of seagrass species in Shark Bay, Western Australia, with notes on their ecology. Aquat Bot 30:305-317

Whiten A, Goodall J, McGrew WC, Nishida T and others (1999) Cultures in chimpanzees. Nature 399:682-685

Submitted: April 4, 2011; Accepted: September 19, 2011

Proofs received from author(s): December 22, 2011 